\title{
THE CREATION OF COLLAPSE DOLINES: A 3D MODELING APPROACH
}

\author{
TRIDIMENZIONALNI NUMERIČNI MODEL NASTANKA \\ UDORNIC
}

\author{
Thomas HILLER ${ }^{1,2}$, Douchko ROMANOV ${ }^{1}$, Franci GABROVŠEK ${ }^{3}$ \& Georg KAUFMANN ${ }^{1}$
}

\begin{abstract}
UDC 551.435.8

Thomas Hiller, Douchko Romanov, Franci Gabrovšek \& Georg Kaufmann: The creation of collapse dolines: A 3D modeling approach

We present a 3D numerical karst evolution model describing mechanisms governing the evolution of collapse dolines. The results confirm the current state of the art of the knowledge about the conditions necessary for a collapse doline to grow. We demonstrate that these geological features develop in karst aquifers, above subsurface rivers flowing through active cave systems or mechanically unstable zones. The mechanisms of growth of single/isolated collapse dolines are generally two dimensional and can be modeled with very dense numerical models. On the other hand, our results demonstrate that there can be more than one location, within a karst system, where the conditions allow the development of a collapse doline. For such complex scenarios a 3D modeling approach and a detailed knowledge of the hydro-geological situation is required in order to correctly predict and describe the development of collapse dolines.
\end{abstract}

Keywords: Three-dimensional, Karst, Modeling, Doline, Limestone.
Izvleček

UDK 551.435.8

Thomas Hiller, Douchko Romanov, Franci Gabrovšek, Georg Kaufmann: Tridimenzionalni numerični model nastanka udornic

$\mathrm{V}$ članku predstavimo tridimenzionalni numerični model razvoja kraških udornic. Rezultati potrjujejo dosedanja spoznanja o pogojih, potrebnih za rast udornic. Pokažemo, da udornice nastajajo kot del razvoja kraškega vodonosnika nad podzemnimi rekami, ki tečejo skozi aktivne jamske sisteme oz. mehansko nestabilna območja. Mehanizem nastanka ene same izolirane udornice lahko pojasnimo $\mathrm{z}$ dvodimenzionalnim numeričnim modelom $\mathrm{z}$ dovolj gosto mrežo. Za študij prostorskega razvoja in porazdelitve sistema udornic potrebujemo 3D numerični model, ki ga lahko ob podrobnem poznavanju hidrogeoloških razmer uporabimo tudi za napovedovanje in interpretacijo pojavljanja udornic na nekem kraškem območju.

Ključne besede: Tridimenzionalni model, kras, udornice, apnenec.

\section{INTRODUCTION}

Karst rocks such as limestone, dolomite, anhydrite, and gypsum can be dissolved by water, either by dissolution of the rock, or in the case of the first two rock types by chemical dissolution in water enriched with carbon dioxide. The removal of rock in fissures and bedding partings creates larger voids and cavities, which results in an

\footnotetext{
${ }^{1}$ Institute of Geological Sciences, Geophysics Section, Freie Universität Berlin, Malteserstr. 74-100, Haus D, 12249 Berlin, Germany, e-mail: georg.kaufmann@fu-berlin.de

${ }^{2}$ Max Planck Institute for Dynamics and Selforganization, Am Fassberg 17, 37077 Göttingen, Germany

${ }^{3}$ Karst Research Institute ZRC SAZU, Titov trg 2, 6230 Postojna, Slovenia

Received/Prejeto: 15.05.2014
} 
efficient drainage of water through the karst rock. Once the cavities grow to a certain size, the void can become unstable and detachment of slabs at the roof of the cavity initiates mechanical breakdown. The breakdown can propagate towards the surface and finally results in a typical karst surface structure such as a collapse doline.

Dolines are closed depressions on the surface, which drain part of the karst landscape; they are, along with poljes and uvalas, typical karst surface features (e.g. Kranjc 2006). The term doline is derived from the Slavic word for valley, dolina, and is used mainly in Europe. In North America the term sinkhole has a similar meaning. Sizes and shapes of dolines are manifold and range from a few meters to hundreds of meters both in diameter and depth (see Fig. 1).

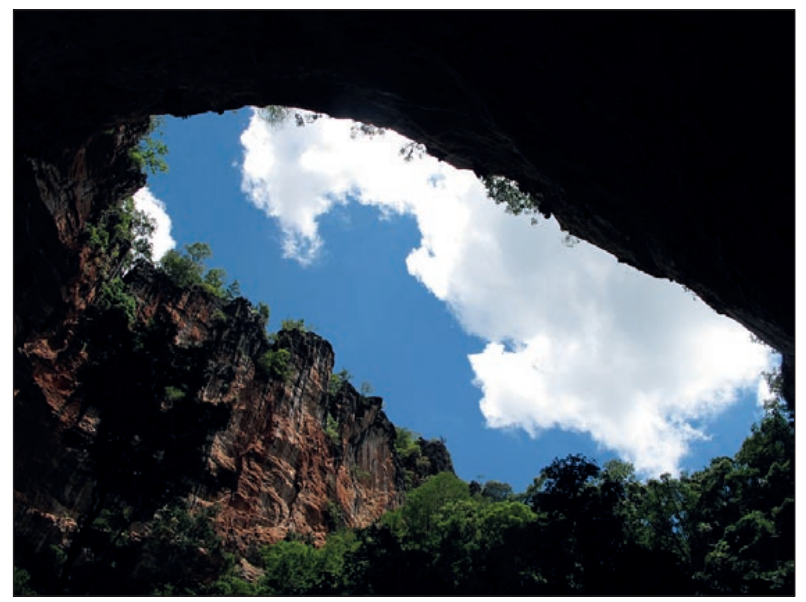

Fig. 1: Example of large collapse dolines: Left: Janelão Cave, Brazil (Photo: Franci Gabrovšek). Right: Crveno Jezero (Red Lake), Croatia (Photo: Douchko Romanov).

Waltham et al. (2005) derived six major types of dolines which may occur in nature as a pure form or as a combination depending on the local geology. We will focus on one of these six types, the collapse dolines, and on an important special subtype of very large collapse dolines, the Tiankengs (heavenly pits) that can be found in the karst regions of China. In terms of genesis a Tiankeng is similar to a collapse doline but has become its own characteristic term in karst science (Zhu \& Waltham 2006). However, the major distinction is made by its size as a Tiankeng has to be at least $100 \mathrm{~m}$ deep and wide.

A general overview on dolines can be found in Waltham et al. (2005), also with a focus on practical implications close to collapse features in karst. Kranjc (2006) gives an overview on large collapse dolines in the Dinaric karst, whereas Waltham (2006) concentrates on large collapse dolines and/or Tiankengs throughout the world. Zhu and Chen (2006) and Zhu and Waltham (2006) focus on Tiankengs especially in China.

Summarizing the given references, there are a few characteristics typical for large collapse dolines:

1. Dolines are generally a few tens to a few hundreds of meters wide and deep.

2. Doline walls are very steep or close to vertical and the floor can be covered with breakdown debris.

3. A large river is either flowing on the floor of the doline or below the ground but not too deep (tens of meters).

4. Dolines can appear in groups all belonging to the same active subsurface cave system (e.g the Dashiwei group or the dolines of the Slovenian Škocjanska jama).

5. Some Dinaric collapse dolines are assumed to be in the range of millions of years old (Gabrovšek 2011 -

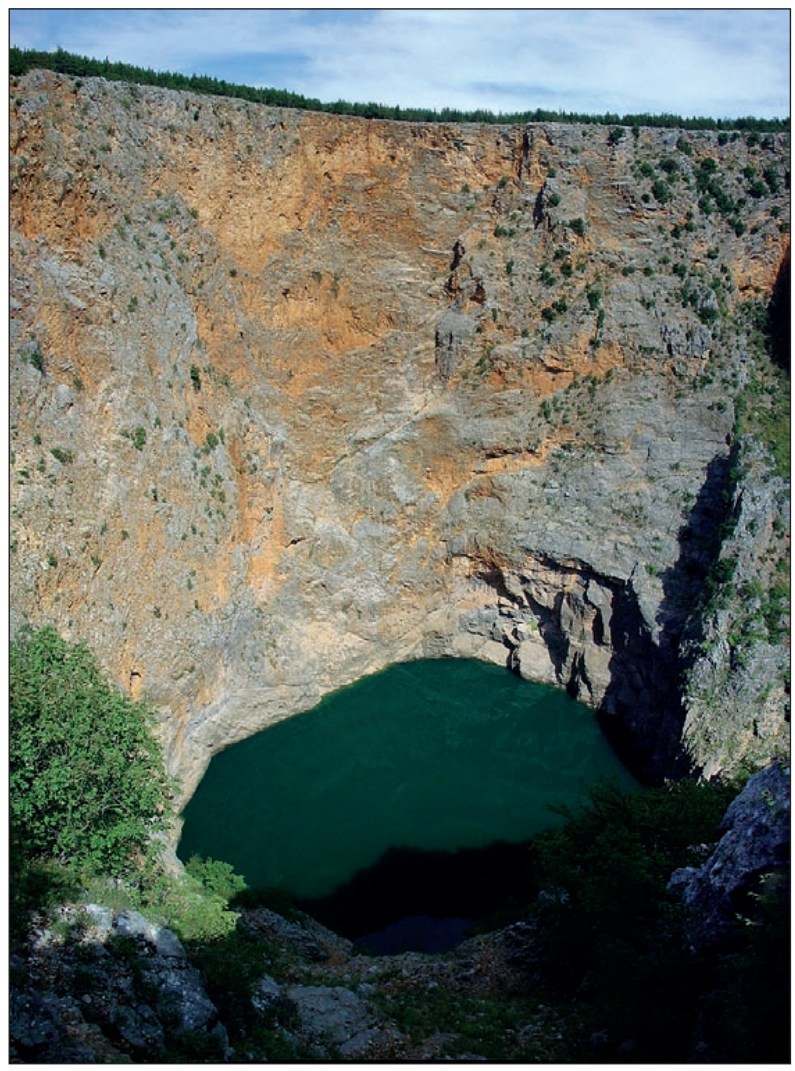

personal communication), whereas Tiankengs can be as young as 200000 years (Zhu \& Chen 2006; Zhu \& Waltham 2006).

Although some dolines, especially smaller ones, can be created by subsidence events or collapse of a cave ceiling, the dolines that are sometimes two orders of magnitude bigger than the largest known cave chambers (Gabrovšek \& Stepišnik 2011) cannot be explained by these processes alone. Thus the collapse of a sub-surface void alone is often not capable to explain the size of the doline. 
A possible explanation on the creation of large collapse dolines has been given by Palmer and Palmer (2006):

- A sub-surface cavity grows to a certain size, and depending on the mechanical stability of the host rock, breakdown of the cavity roof starts.

- The collapsed material accumulates along the floor of the cavity, partially blocking water flow and thus increasing the hydraulic pressure head in the cavity.

- Here, the blocks can be removed by mechanical erosion, and more efficiently by chemical dissolution.

- The void propagates upwards into the overburden.

- If the overburden is entirely made up of soluble rock, the material can be removed completely and after the final collapse of the remaining rock ledge, a deep doline remains. If the overburden comprises insoluble rocks, part of the debris accumulates at the bottom of the doline.

This concept was modeled by Gabrovšek and Stepišnik (2011) with a 2D karst evolution model to estimate the material removal in such a crushed zone. In terms of material removal rates their model is in quanti- tatively good agreement when compared to the size and evolution time of known dolines.

The goal of our paper is to develop the numerical approach of Gabrovšek and Stepišnik (2011) further and extend it into the third dimension. We use the KARSTAQUIFER tool (e.g. Kaufmann et al. 2010) to simulate the evolution of a karst aquifer, and we define several steps for our analysis: (i) In a first step we rebuild the crushed zone from the 2D model of Gabrovšek and Stepišnik (2011) with our KARSTAQUIFER code and compare the evolution of both models to find a common basis for the further simulations. (ii) As large collapse dolines often appear in groups we extend the model and embed several crushed zones into a single 3D domain. Because so far erosional processes are not directly implemented in our model, the creation of collapse dolines by means of surface lowering due to the crushed zones is simulated with a distinct collapse mechanism. (iii) By activating more than one crushed zone in a single domain, we then study the evolution of several collapse dolines and their interaction.

\section{THEORY}

The term karstification generally describes the alteration of soluble bedrock such as limestone or gypsum by means of dissolution. Water penetrates into the karst bedrock through fissures and bedding partings, removes material and the voids are widened to cavities and caves. In general, modeling karstification can be partitioned into two major sub-steps: The first is calculating flow of water depending on the hydraulic conductivity of the host rock and the hydrological boundary conditions. The second is to calculate the dissolutional widening determined by flow and calcium concentration and the transport of the dissolved calcium.

The flow of water through a fissured and fractured aquifer can be described by a transient continuity equation:

$\frac{\partial}{\partial x}\left(K(t) \frac{\partial h}{\partial x}\right)+\frac{\partial}{\partial y}\left(K(t) \frac{\partial h}{\partial y}\right)+\frac{\partial}{\partial z}\left(K(t) \frac{\partial h}{\partial z}\right)=S \frac{\partial h}{\partial t}$,

where $K(t)\left[m s^{-1}\right]$ is the time-dependent hydraulic conductivity, $\mathrm{S}\left[\mathrm{m}^{-1}\right]$ the specific storage and $h[\mathrm{~m}]$ the hydraulic head as a sum of elevation head $z[m]$ and pressure head $p[m]$. Furthermore, $x[m], y[m]$ and $z[m]$ denote the spatial coordinates, and $t[s]$ is time. We solve (1) by means of the finite-element method (e.g. Istok 1989), us- ing three-dimensional parallelepiped finite elements for the rock matrix and linear bar elements for fissures and bedding partings to assemble the modeling domain.

The hydraulic conductivity of the rock matrix $K=K_{m}$ (see Tab. 1) is fixed to a constant value for all calculations. Therefore, the increase of hydraulic conductivity over time is controlled only by the dissolutional widening of the conduits. For laminar flow the hydraulic conductivity $K_{c}^{l}$ of such a conduit is given by

$K_{c}^{l}=\frac{g d^{2}}{32 v}$,

where $g\left[m s^{-2}\right]$ is the gravitational acceleration, $d[m]$ the conduit diameter and $v\left[\mathrm{~m}^{2} \mathrm{~s}^{-1}\right]$ the kinematic viscosity of the solution. If the flow inside the conduit becomes turbulent the non-linear Darcy-Weissbach flow law is applied. The hydraulic conductivity $K_{c}^{t}$ of a conduit is then given by

$K_{c}^{t}=\frac{2 g d}{f}$,

where $f$ is the friction factor, which has to be calculated in dependence of the Reynolds number (see e.g. Kaufmann 2009). Each conduit can be assigned with an individual in- 
itial diameter $d_{0}$ to account for any kind of heterogeneous (e.g. statistical) distribution of the hydraulic conductivity.

Tab. 1: Standard model parameters.

\begin{tabular}{|c|c|c|c|}
\hline Model Parameters & Symbol & Unit & Value(s) \\
\hline \multicolumn{4}{|l|}{ Model domain: } \\
\hline Length & $X$ & $m$ & $\leq 500$ \\
\hline Width & $Y$ & $m$ & $\leq 500$ \\
\hline Height & $Z$ & $m$ & $\leq 50$ \\
\hline Horizontal resolution & $d x, d y$ & $m$ & $5-25$ \\
\hline Vertical resolution & $d z$ & $m$ & $1-5$ \\
\hline Nodes & $N_{n}$ & {$[-]$} & 42135 \\
\hline Elements & $N_{\epsilon}$ & {$[-]$} & 37856 \\
\hline Conduits & $N_{c}$ & {$[-]$} & 116494 \\
\hline Matrix conductivity & $K_{m}$ & $\mathrm{~m} \cdot \mathrm{s}^{-1}$ & $1 \times 10^{-5}$ \\
\hline \multicolumn{4}{|l|}{ Limestone chemisty } \\
\hline Linear kinetic exponent & $n_{1}$ & {$[-]$} & 1 \\
\hline High-order kinetic exponent & $n_{2}$ & {$[-]$} & 4 \\
\hline Linear rate constant & $k_{1}$ & $\begin{array}{l}\mathrm{mol} \cdot \mathrm{m}^{-2} \\
\cdot \mathrm{s}^{-1}\end{array}$ & $4 \times 10^{-7}$ \\
\hline Calcium concentration & $c$ & $m o l \cdot m^{-3}$ & $\begin{array}{l}c_{\text {in }}<c \\
<c_{\varepsilon q}\end{array}$ \\
\hline Initial calcium concentration & $c_{i n}$ & $\mathrm{~mol} \cdot \mathrm{m}^{-3}$ & 0 \\
\hline Calcium switch concentration & $c_{s}$ & $\mathrm{~mol} \cdot \mathrm{m}^{-3}$ & $9.9 c_{\varepsilon q}$ \\
\hline Temperature & $T$ & & 10 \\
\hline $\begin{array}{l}\text { Partial pressure of carbon } \\
\text { dioxide }\end{array}$ & $\mathrm{pCO}_{2}$ & atm & 0.05 \\
\hline
\end{tabular}

The enlargement of the conduit diameter by chemical dissolution is described by the relation

$d\left(t_{i}\right)=d\left(t_{i-1}\right)+F \frac{m_{M I N}}{\rho_{M I N}}\left(t_{i}-t_{i-1}\right)$,

Here, $t_{i-1}$ and $t_{i}$ are two consecutive time steps, $F\left[\mathrm{~mol} \mathrm{~m} \mathrm{~m}^{-2} \mathrm{~s}^{-1}\right]$ is the calcium flux rate which describes the removal of bedrock per unit area and time, $m_{M I N}\left[\mathrm{~kg} \mathrm{~mol}^{-1}\right]$ is the molar mass and $\rho_{M I N}\left[\mathrm{~kg} \mathrm{~m}^{-3}\right]$ the density of the soluble mineral (calcite in this case), respectively.

The flux rate $F$ as a function of calcium concentration has been intensively studied (e.g. Buhmann \& Dreybrodt 1985a,b; Dreybrodt 1988; Eisenlohr et al. 1999; Kaufmann \& Dreybrodt 2007; Plummer et al. 1978; Svensson \& Dreybrodt 1992) and can be described by the rate law
$F=k_{i}\left(1-\frac{\mathcal{C}}{c_{e q}}\right)^{n}, i=1, n$

with $k_{i}\left[\mathrm{~mol} \mathrm{~m}^{-2} \mathrm{~s}^{-1}\right]$ a rate coefficient, $c\left[\mathrm{~mol} \mathrm{~m}^{-3}\right]$ the actual concentration of $\mathrm{Ca}^{2+}$ in the water, $c_{\epsilon q}\left[\mathrm{~mol} \mathrm{~m}^{-3}\right]$ the equilibrium concentration with respect to calcite and $n_{i}[-]$ a power-law exponent. The coefficient $k_{i}$ and the exponent $n_{i}$ are characteristic parameters for the bedrock mineral, and depend on the amount of undersaturation with respect to calcite in the subsurface water. For $c \leq c_{s}$ the system exhibits linear kinetics, $i=1$ with in eq. 5 . This leads to coefficients and. For $c>c_{s}$ the system exhibits higher-order kinetics where the rate becomes non-linear and the coefficients $k_{2}$, and $n_{2}$ are used (see Tab. 1 for details). The switch concentration in our model is $c_{s}=0.9 c_{e q}$.

The calcium equilibrium concentration depends on temperature $T\left[{ }^{\circ} \mathrm{C}\right]$ and carbon-dioxide pressure $p[\mathrm{~atm}]$. Using a simplified charge balance valid for karst water, an analytical expression can be used (e.g. Dreybrodt 1988):

$c_{e q}(T, p)=\sqrt[3]{\frac{K_{1}(T) K_{C}(T) K_{H}(T)}{4 K_{2}(T) \gamma_{\mathrm{Ca}^{2+}} \gamma_{\mathrm{HCO}_{3}^{-}}^{2}}} p$.

With $K_{H}(T)$ the equilibrium constant for the dissolution of atmospheric carbon dioxide into water (Henri constant), $K_{0}(T)$ the equilibrium constant for the reaction of water and carbon dioxide to carbonic acid, $K_{1}(T)$ and $K_{2}(T)$ the equilibrium constants for the dissociation of carbonic acid into bicarbonate, carbonate, and hydrogen (e.g. Usdowski 1982), $K_{C}(T)$ the equilibrium constant for dissolved calcite, $\gamma_{\mathrm{Ca}^{2+}}$ and $\gamma_{\mathrm{HCO}_{3}^{-}}^{2}$ the activity coefficients for calcium and bicarbonate (e.g. Harned \& Hamer 1933). The carbon-dioxide pressure remains constant in the open-system case, as carbon dioxide can be replenished from the atmosphere, but decreases, once the solution becomes decoupled from the atmosphere in the closed-system case:

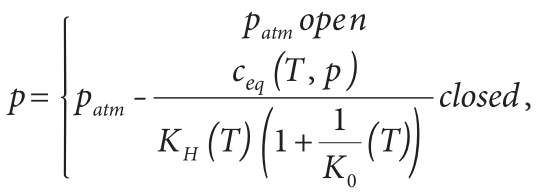

with $p_{a t m}[\mathrm{~atm}]$ the initial carbon-dioxide partial pressure.

For more details on the implementation of the KARSTAQUIFER model, see Kaufmann et al. (2010) and Hiller et al. (2011). See Tab. 1 for the values we have used within this study. 


\section{MODEL}

The conceptual model for the evolution of a collapse doline is shown in Fig. 2. Here, $\mathbf{A}$ is the karst rock in which the collapse doline $\mathbf{B}$ is going to evolve. Following Palmer and Palmer (2006), one of the necessities to create collapse dolines are fault zones inside the rock. These fault zones mark the boundaries of a mechanically unstable crushed zone. The fault planes are indicated by the dashed lines in Fig. 2. Another necessity in the presented concept is a subsurface passage for water to enter (D1) and leave (D2) the cavity present at the bottom of the crushed zone. As this passage crosses the highly fractured bedrock, breakdown of parts of the cavity roof block the passage and material accumulates in the crushed zone $\mathrm{C}$, which resembles a highly fissured part of the domain. The hydraulic gradient increases and incoming aggressive water enlarges passages between the blocks in the crushed zone by chemical dissolution. The dissolved material is leaving the crushed zone through the output passage. Because the crushed zone is mechanically unstable, the removal of the crushed blocks induces further collapse of the cavity roof, with upward propagation of the void space, and finally the creation of a collapse doline. This breakdown is indicated by the thin circle lines below the doline $c y l$ inder in Fig. 2. Note again, that the bedrock is only removed by dissolution, and the model does not account for the real mechanical properties of the bedrock and/or erosional processes that might as well remove collapsed material from the bottom of the crushed zone.

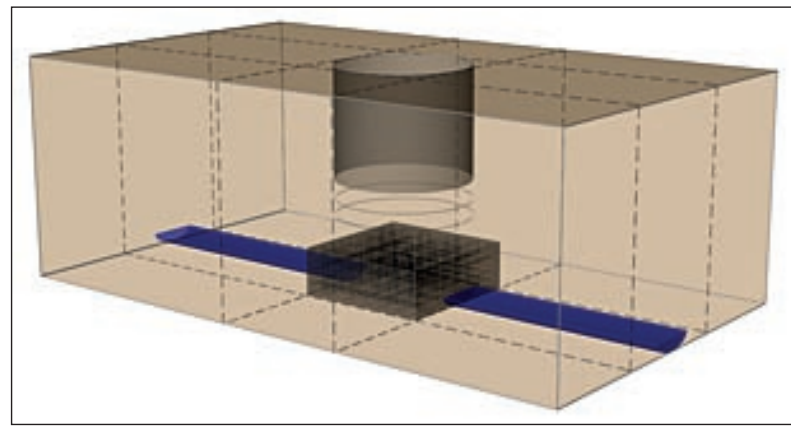

Fig. 2: Conceptual model of the doline model: A karst bedrock; $B$ collapse doline; $C$ crushed zone; D1 subsurface passage/stream (input); D2 subsurface passage/stream (output); the dashed lines represent fault planes inside the bedrock; modified after Gabrovšek \& Stepišnik (2011).

\subsection{D MODEL DOMAIN AND BOUNDARY CONDITIONS}

The model domain used in this work for simulating the doline evolution is shown in Fig. 3. The relevant modeling parameters are summarized in tables 1 and 2.
The model domain for the final $3 \mathrm{D}$ doline models is a $500 \times 500 \times 50 \mathrm{~m}^{3}$ limestone block. The grid discretization varies between $d x=d y=5 \mathrm{~m}$ inside and $d x=d y=25 m$ outside of the crushed zones. The vertical grid discretization varies between $d z=1 \mathrm{~m}$ and $d z=5 \mathrm{~m}$, respectively. Due to the use of a rectangular network and a constant amount of grid nodes in each spatial direction, the crushed zones are not implemented as pure local grid refinements (see Fig. 3). In other words, the smaller distance between the nodes in the crushed zones results in small distance between the conduits entering and exiting these areas also outside of them. The effect can be seen within the green square and Fig. $3 \mathrm{~b}$ for example. We need small distance between the nodes in crushed zone 2 (CZ2). For this reason all conduits that enter and leave this zone (coordinates X (100 to 200) and Y (100 to 200) are closer to each other in comparison to the conduits not crossing CZ2 (coordinates X (0 to 100), Y (0 to 100)). This leads to domain regions with a higher spatial resolution than necessary (e.g. between the crushed zones) and has to be considered in the interpretation of the results. The hydraulic conductivity of the matrix is $1 \times 10^{-5} \mathrm{~ms}^{-1}$. In contrast to this uniform conductivity, which is defined for each block inside the modeling domain, the conduit network is represented by a rectangular network with a log-normal statistical distribution of initial conduit diameters. The parameters describing this distribution for the whole domain are $\widehat{d_{0}}=0.05 \mathrm{~mm}$ and $\sigma=0.75$, which represents an intact (or immature) and only slightly fissured karst bedrock. The blue face in Fig. 3a marks the region where a constant head boundary condition (BC) $(H=10 \mathrm{~m})$ is applied to the grid nodes. On the opposite domain boundary (not visible in Fig. 3a) a constant head $\mathrm{BC}$ of $H=0 \mathrm{~m}$ is applied to induce flow through the domain in positive $x$-direction.

The domain is intersected by two active subsurface cave passages (black lines in Fig. 3a) passing through the model in $x$-direction at $z=0 \mathrm{~m}$. The passages have an initial conduit diameter of $d_{0}=0.13 \mathrm{~m}$ to obtain flow rates between $1 \mathrm{~m}^{3} \mathrm{~s}^{-1}$ and $5 \mathrm{~m}^{3} \mathrm{~s}^{-1}$, depending on the chosen setup and applied boundary conditions. These flow rates are in agreement with values used in previous studies or reported from the field (e.g. Gabrovšek \& Stepišnik 2011; Palmer \& Palmer 2006). The denser parts of the rectangular conduit network on Fig. 2 visualize the areas which we can model as crushed zones. We use/alter three of these four zones depicted in the figure for creating the different models calculated for this work. The areas are marked by CZ (see Fig. 3). The initial diameters of the conduits in the zone are assigned according to the statistical distribution, which is chosen for the whole 


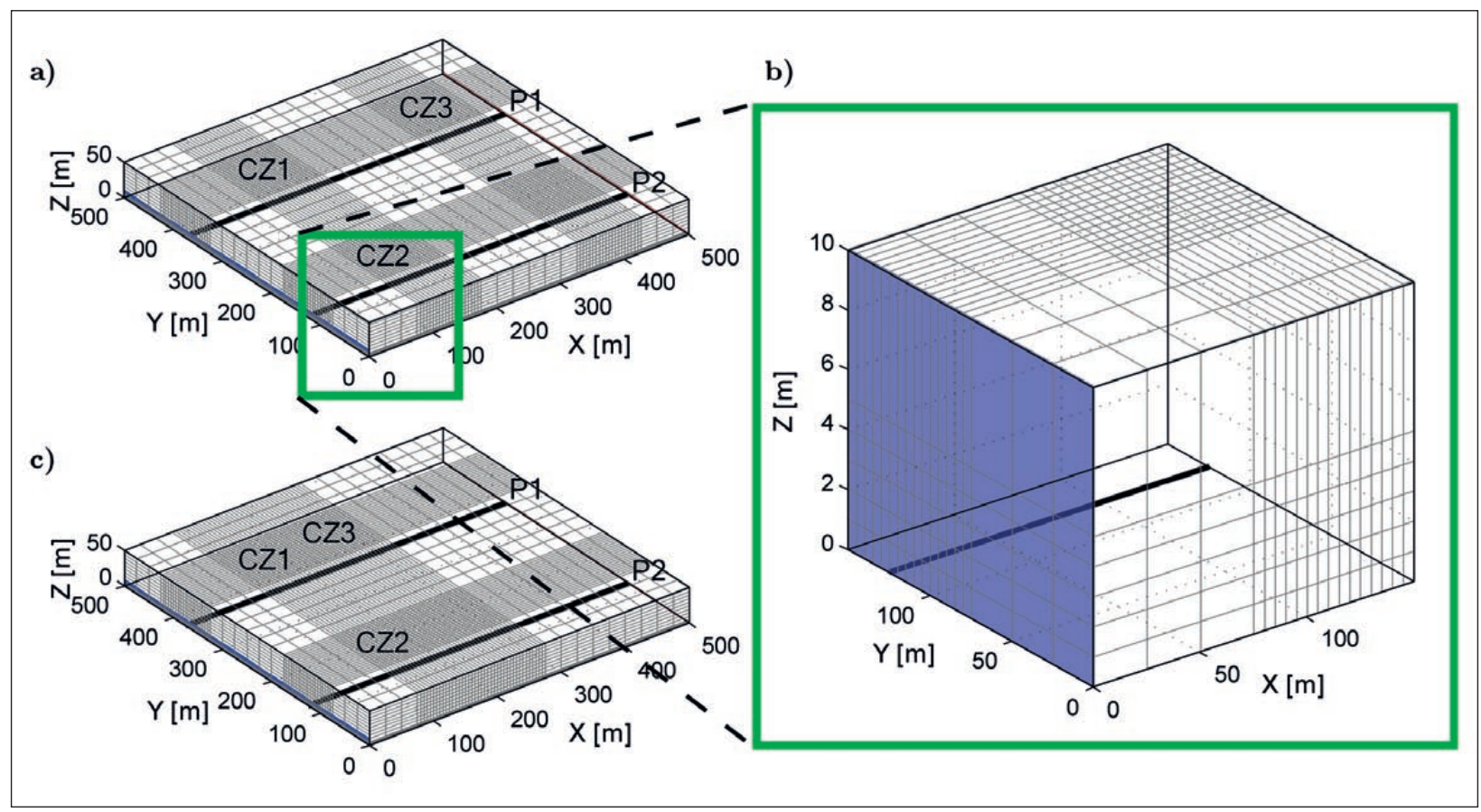

Fig. 3: 3D doline model setup: a) Setup for model 1 and model 3; four zones with increased resolution due to the regular grid, but only one to three active crushed zones (CZ), two subsurface passages (black lines), see also Tab. 2. Blue face marks const. head boundary condition of $H=10 \mathrm{~m}$ and red face const. head boundary condition of. $b$ ) Green frame marks enlarged part from a, note that here the grid is out of scale; $c$ ) setup for model 2.

modeling domain. If one of the zones is activated and modeled as a crushed zone, its hydraulic conductivity is modified by assigning new initial conduit diameters to the conduits inside this zone. With this approach, the mechanical weakening (enlarged fissures and fractures are already present) of the crushed zone is simulated. The parameters for these conduits are $\hat{d}_{0}=0.05 \mathrm{~mm}$ and $\sigma=0.75$ and are chosen following the calibration presented in 4.1 .

\subsection{CRUSHED ZONE - COLLAPSING MECHANISM}

Gabrovšek and Stepišnik (2011) used two mechanisms to mimic the material removal processes inside a crushed zone. The first one they called continuous infilling and is similar to the limited widening scheme presented by Romanov et al. (2010). If a fracture reaches a critical aperture width $A_{\text {lim }}$ then its enlargement is stopped but the dissolution is still active. Therefore, material is removed in every time step but the fracture aperture is always reset to $A_{\text {lim }}$. With this approach, a continuous collapse of the crushed blocks is assumed, with voids between the blocks keeping their size, and a more or less constant flux rate (removal rate) is established. The second mechanism they called discontinuous collapsing which resets the fracture apertures to the initial or smaller value, if a critical aperture width is reached. After this resetting, the growth of the fracture starts again. This second approach mimics the periodically collapsing breakdown area.

In this work we use a variant of the discontinuous collapsing mechanism from Gabrovšek and Stepišnik (2011): The general implementation is shown in Fig. 4 (note that the dimensions are not to scale). Fig. 4a shows a fraction of the model domain. The initially small passages inside the crushed zone mark passages between collapsed blocks. These passages are enlarged over time by dissolution (Fig. 4b), and the breakdown area becomes mechanically instable once the passages reach a critical size $d_{c r i t}$, then they collapse again, reducing the passages between the blocks. Thus a periodic behavior of the breakdown area is simulated. The smaller diameter of the passages is derived by the same statistical parameters $\hat{d}_{0}$ and $\sigma$ that are initially used for the conduits in the corresponding crushed zone. The difference between the critical and the small diameter after collapsing $\Delta d=d_{\text {crit }}-d_{\text {imit }}$ is used as the maximal possible value for surface lowering (Fig. 4c).

In our model we represent the intersection of bedding partings and fractures of the bedrock by cylindrical conduits. We assume that a limestone block can collapse (move virtually downward) only if all four bordering fractures (conduits) have reached a critical size. Here, by limestone block we mean each cuboid whose edges are conduits. The lengths of these conduits are $d x, d y$ and $d z$. 


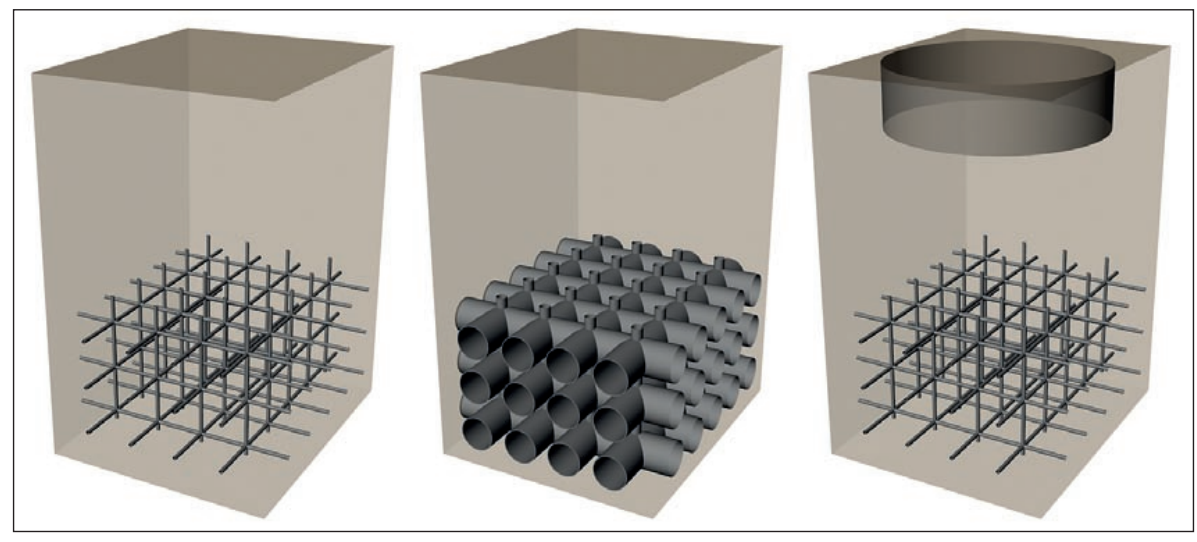

Fig. 4: Simulated mechanical collapse of the doline above the crushed zone: a) initial situation of the conduit network inside the crushed zone; b) horizontal conduits have reached a certain critical diameter; $c$ ) the horizontal conduits have collapsed and the topography is lowered accordingly.

We further constrain this collapse procedure and only allow the collapse of one depth layer inside the crushed zone if at least $75 \%$ of all conduits in this layer have reached the critical diameter. If in a single time step this criterion is fulfilled, then all conduits in this layer are reset and the surface collapses.

\section{RESULTS}

\subsection{D MODEL CALIBRATION}

As this doline model is inspired by the $2 \mathrm{D}$ model of Gabrovšek and Stepišnik (2011) and is consequently a $3 \mathrm{D}$ extension of their $2 \mathrm{D}$ approach, the first objective is to compare 2D results of Gabrovšek and Stepišnik (2011) with the results from the 3D KARSTAQUIFER code used here. Therefore, we first consider only the crushed zone and use the determined values from the calibration when embedding the crushed zones into the $3 \mathrm{D}$ domain as it is shown in Fig. 3. For the calibration runs we use the same grid layout as Gabrovšek and Stepišnik (2011), which means one layer of a $200 \times 200 \mathrm{~m}^{2}$ conduit network with a horizontal spacing of $d x=d y=2 \mathrm{~m}$. Furthermore, we use the same boundary conditions in our setup as in the original 2D model. To find a comparable initial conduit diameter distribution that simulates the evolution of their dual-fracture network, we test many different non-uniform conduit networks with varying distribution parameters. To pick the most suitable initial conduit diameter distribution out of the tested set, we consider only the breakthrough time TB of the resulting flow curve. This is done because we are mainly interested in a similar temporal evolution of the model as the amount of flow (the pure amplitude) through the domain will of course differ due to the different fracture network geometries (fractures in the 2D model - conduits in the 3D model).

Fig. 5a shows a set of the tested conduit diameter distributions. All distributions have a mode of $\hat{d}_{0}=0.3-0.6 \mathrm{~mm}$ and a varying within larger boundaries standard deviation $\sigma$. The wider the distribution gets the more non-uniform the conduit network will be. For $\sigma=0.35$ (black curve) the distribution of the conduit diameters spans about one order of magnitude, whereas for $\sigma=1$ (green curve) it spans about four orders of magnitude, respectively. In Fig. $5 \mathrm{~b}$ the corresponding flow curves are plotted for 3000 years of evolution together with the 2D flow curve (dashed black curve) from Gabrovšek and Stepišnik (2011). All curves are characterized by an initially low flow rate, which increases due to the enlargement of fractures by dissolution. Within a short time period, flow rates increase by several orders of magnitude, an event called breakthrough and the corresponding time breakthrough time. After breakthrough, the flow rate increases with a much slower rate. When comparing flow rates for the $2 \mathrm{D}$ and $3 \mathrm{D}$ models, we find that the breakthrough times of the red curve with $\sigma=0.75$ and the 2D curve are almost identical. Although the amount of flow before and after breakthrough of these two curves differs, it is within one order of magnitude and we will regard this as acceptable. Once again, we regard this as acceptable because our initial calibration criterion was the evolution/breakthrough time and not the absolute flow rate. The flow rates between both models, the one suggested by Gabrovšek and Stepišnik cannot be the same for similar evolution times, because in KARSTAQUIFER we use conduits and not fractures.

Because in the end we want to study the interaction of several crushed zones (dolines), it is not feasible to stick to the grid discretization for the whole domain. This would lead to model sizes in the range of $400 \times 400 \times 25$ 


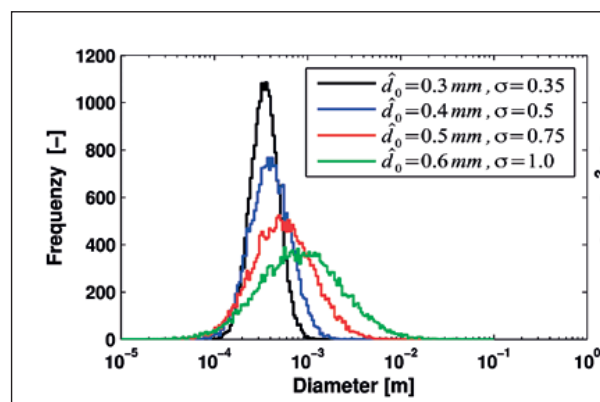

a) $d_{0}$ distrib. for calibration models

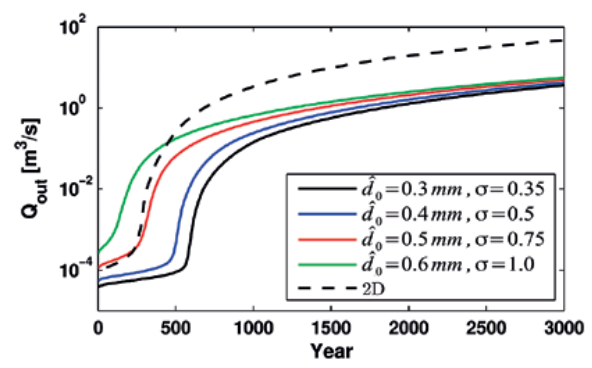

c) flow curves for calibration models $d x=d y=5 \mathrm{~m}$

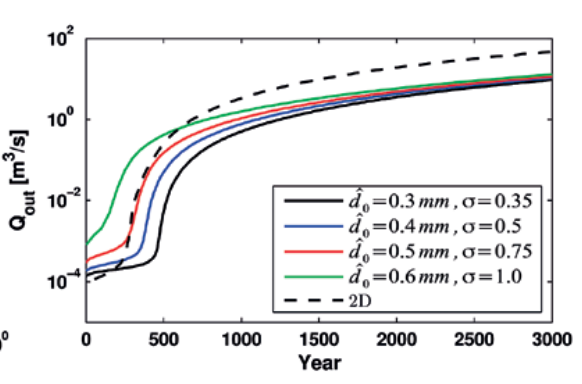

b) flow curves for calibration models $d x=d y=2 m$

Fig. 5: Doline model calibration: a) initial diameter distributions for different $3 D$ models to calibrate the $3 D$ code to the $2 \mathrm{D}$ model; b) corresponding flow curves to a plus the $2 D$ flow curve; c) flow curves for calibration models with a coarser network.

nodes and therefore exceed the available computational power. To cope with this limitation the crushed zone resolution is decreased to $d x=d y=5 \mathrm{~m}$. To check if this coarsening has an effect on the breakthrough time of the crushed zone, we simulate the evolution with the same conduit diameter distributions and boundary conditions as the model with the $d x=d y=2 m$ discretization from before. The coarser network for the model with $\sigma=0.75$ (red curve in Fig. 5c) fits the 2D curve comparably well as for the dense network so that these are the final distribution parameters that will be chosen for the $3 \mathrm{D}$ model (see also Tab. 2).
We thus have determined the initial conduit diameter distribution yielding comparable results to the $2 \mathrm{D}$ model and proceed discussing 3D scenarios.

\subsection{D EVOLUTION MODELS}

\subsubsection{MODEL 1 - ONE ACTIVE CRUSHED ZONE}

The first 3D doline model that is presented has the following setup: Two subsurface passages cross the domain as shown in Fig. 3 and the head difference between entrance and exit is. So far only one crushed zone $(\mathrm{CZ1})$ is

Tab. 2: Doline model parameters.

\begin{tabular}{|c|c|c|c|c|}
\hline Name & $\begin{array}{c}x \text {-extent } \\
(d x)\end{array}$ & $\begin{array}{c}y \text {-extent } \\
\text { (dy) }\end{array}$ & $\begin{array}{c}\text { z-extent } \\
(d z)\end{array}$ & network \\
\hline Domain size & $\begin{array}{c}500 \mathrm{~m} \\
(5-25 \mathrm{~m})\end{array}$ & $\begin{array}{c}500 \mathrm{~m} \\
(5-25 \mathrm{~m})\end{array}$ & & $\hat{d}_{0}=0,05 \mathrm{~mm}, 6=0.75$ \\
\hline \multicolumn{5}{|c|}{ Crushed zones (CZ): } \\
\hline CZ1 & $75-175 m$ & $325-425 \mathrm{~m}$ & $0-5$ & $\hat{d_{0}}=0,05 \mathrm{~mm}, 6=0.75$ \\
\hline CZ2 & $75-175 m$ & $75-175 \mathrm{~m}$ & $0-5$ & $\hat{d}_{0}=0,05 \mathrm{~mm}, \sigma=0.75$ \\
\hline CZ3, model $1 \& 3$ & $325-425 m$ & $325-425 \mathrm{~m}$ & $0-5$ & $\widehat{d_{0}}=0,05 \mathrm{~mm}, \sigma=0.75$ \\
\hline CZ3, model 2 & $\begin{array}{c}175-275 \mathrm{~m} \\
(5 \mathrm{~m})\end{array}$ & $\begin{array}{c}325-425 \mathrm{~m} \\
(5 \mathrm{~m})\end{array}$ & $\begin{array}{l}0-5 \\
(1 \mathrm{~m})\end{array}$ & $\hat{d}_{0}=0,05 \mathrm{~mm}, 6=0.75$ \\
\hline \multicolumn{5}{|l|}{ Passages } \\
\hline P1 & $0-500 \mathrm{~m}$ & $375 \mathrm{~m}$ & $0 \mathrm{~m}$ & $d_{0}=0.13 \mathrm{~m}$ \\
\hline P2 & $0-500 \mathrm{~m}$ & $125 \mathrm{~m}$ & $0 \mathrm{~m}$ & $d_{0}=0.13 \mathrm{~m}$ \\
\hline
\end{tabular}




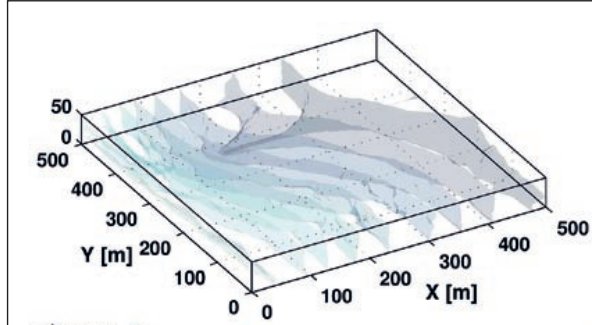

a) year: 0

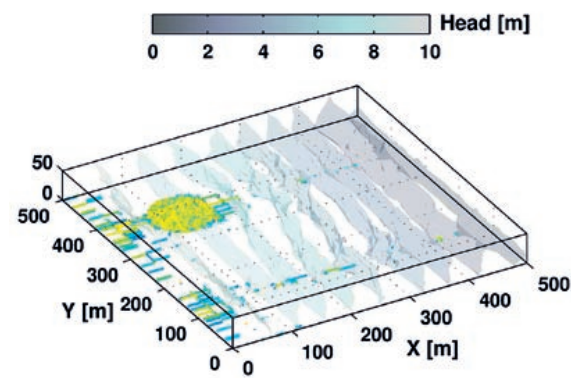

c) year: 1300

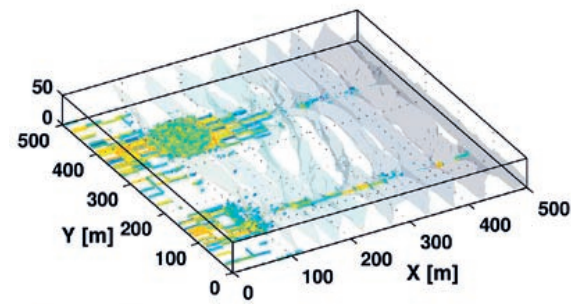

e) year: 3000

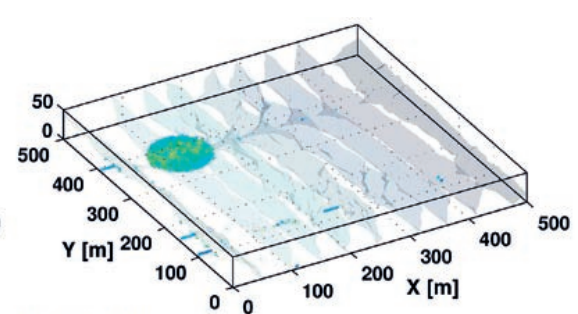

b) year: 300

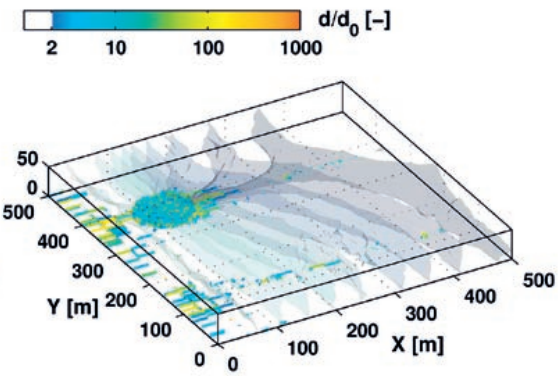

d) year: 1400

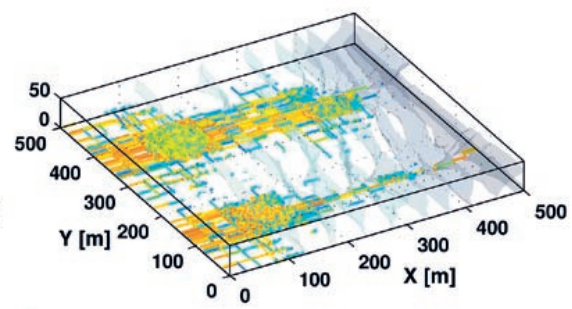

f) year: 6000
Fig. 6: Conduit diameter evolution of the $3 D$ doline model 1 (one active crushed zone) for different snapshots in time. Below each subplot the year is given; plotted are the isosurfaces of constant head from low (dark grey) to high (light grey) values and the relative increase of the conduit diameter compared to the initial diameter on a log-scale from 2 (blue) to $\geq 1000$ (orange). activated to study the evolution of a single crushed zone inside our model domain. The domain and crushed zone parameters are summarized in Tab. 2. Because crushed zones CZ2 and CZ3 are not activated their initial network parameters are the same as the global network parameters. The evolution of model 1 is shown in Fig. 6 (evolution of model with six snapshots in time) and in Fig. $9 a+b$ (relevant system parameters as a function of time).

Fig. 6 shows the evolution of the conduit diameters in model 1 for six snapshots in time over 6000 years. Shown are the isosurfaces of constant head from low (dark gray) to high (light gray) values and the relative increase of the conduit diameter compared to the initial diameter on a log-scale from a factor of 2 (blue) to a factor of $\geq 1000$ (orange). For enhanced visibility only the conduits that have grown at least by a factor of $d / d_{0}>2$, are shown.

Fig. 6a shows the initial head distribution inside the domain. We have assumed that the roof of the cavity started to collapse, creating a breakdown area (crushed zone), which inhibits flow through the cave passage P1. This is clearly seen from the isosurfaces of constant head that show an increase of the hydraulic gradient close to the crushed zone (the closer the isosurfaces are the higher is the gradient and vice versa).

After 300 years of evolution (Fig. 6b), the crushed zone has significantly evolved, when compared to the rest of the domain. The conduit diameters are generally increased by a factor of $d / d_{0} \approx 10$ (cyan)whereas in the central part of the domain also larger conduits are visible (increased by a factor of $d / d_{0} \approx 100$ (yellow)). The reason for this enlargement is twofold: First, passage P1 feeds the crushed zone directly with undersaturated water which locally decreases the calcium concentration of the water and thereby increases the dissolutional strength. Secondly, due to the larger conduits, the crushed zone is more conductive and thus focusing flow and hence the calcium aggressive water is more likely to be transported into the crushed zone than flowing around it.

After 1300 years of evolution (Fig. 6c), the conduits inside the crushed zone are significantly enlarged by more than a factor of $d / d_{0} \approx 100$. The collapsing is soon to happen as most of the conduits inside one layer of the crushed zone have already reached their critical diameter. But also along the second passage (without an ac- 
tivated crushed zone) a few conduits have increased in size because the passage allows for aggressive water to be transported through the whole domain and dissolve material along its extent.

Fig. $6 \mathrm{~d}$ shows the domain after 1400 years of evolution and effectively right after the collapse has happened. The crushed zone is now blocked again (see the increase of the hydraulic heads in the crushed zone) and the conduit diameters are reset to a value similar to their initial value (blueish colors). This cycle continues for the remaining time steps until the simulation is stopped after 6000 years.

Figs. $6 \mathrm{e}+\mathrm{f}$ show the domain after 3000 and 6000 years, respectively. After 3000 years, few hundred years after the second collapsing event, the zone of enlarged conduits downstream of the crushed zone has reached half of the domain. Because the crushed zone acts like a natural divergence, aggressive water is released along the whole width of the crushed zone. In contrast to this, along the second passage, without an active crushed zone, only the conduits close to the passage have enlarged deep into the domain. After 6000 years the wide enlarged zone downstream of the crushed zone has almost reached the boundary of the domain. Also conduits along the second passage have enlarged especially inside the non activated crushed zone. The reader may notice that it looks like as if there is a stronger evolution inside the non activated crushed zones. This is a side effect of the domain layout and the increased grid resolution there.

In Fig. 9a the temporal evolution of the flow through passage 1 is shown. The local breakthrough event, or in other words the fast increase of flow through the passage, happens within the first 150 years. The parts of the passage that were blocked by the crushed zone get enlarged very quickly and the flow increases by roughly two orders of magnitude. After this first steep increase the enlargement process slows down significantly and continues until $\approx 1400$ years. At that time the first collapse of crushed zone CZ1 occurs, passage 1 is blocked again and consequently the flow rates drop by two orders of magnitude (compare Fig. 6d). After the collapse the high flow rates are quickly reestablished due to the consecutive breakthrough event, comparable with the beginning of the simulation. The flow curve shows three more collapse events at $\approx 2700, \approx 4000$ and $\approx 5200$ years, respectively. Fig. $9 \mathrm{~b}$ shows the estimated cumulative loss of surface volume above the crushed zone (black line and axis). The corresponding topographical height above the crushed zone is shown in red. In the presented model always the maximal possible amplitude of a collapse event is chosen, so that the volume $v_{C Z}$ that is removed from the surface directly above a crushed zone is given by
$V_{C Z}=A_{C Z} \max \left(d_{c r i t}^{i}-d_{n \in w}^{i}\right)$.

Here $A_{C Z}$, is the total area of the crushed zone and the new reset diameter of a single conduit $i$ inside the crushed zone. In our approach, the total volume loss at a certain time is given by the surface area $A_{C Z}$ and the largest difference between pre- and post-collapsing diameter $d_{n e w}$. As explained in 3.2, this procedure accounts for the representation of fractures by conduits in our model and allows a surface lowering of $\Delta d[\mathrm{~m}]$. Within the model, the locations of the nodes inside the crushed zone are not changed and the volume loss/height difference is directly applied to the surface nodes (as if the whole column of bedrock has moved downwards). Fig. $9 \mathrm{~b}$ shows that one collapse event removes $\approx 2200 \mathrm{~m}^{3}$ of material leading to a surface lowering of $\approx 0.25 \mathrm{~m}$. The visible periodicity of the model is determined by the critical diameter $d_{\text {crit }}$ which is, from a mechanical point of view, rather small within our model but chosen for practical reasons. We always apply a critical diameter of $d_{\text {crit }}=0.05 \mathrm{~m}$ to allow at least four big collapse events within 6000 years of evolution. If a larger value for $d_{c r i t}$ would have been chosen the simulation times would have been increased significantly. Furthermore, a larger $d_{\text {crit }}$ would allow for larger conduits to develop before a collapse event. We assume that in such cases a model has to consider not only the dissolution processes (as done by KARSTAQUIFER) but also to account for the mechanical erosion and the mechanical stability within the bedrock. Such scenarios are outside of the scope of this paper and will not be considered. Fig. 9b shows that after 6000 years of evolution the surface has been lowered by $\approx 1.25 \mathrm{~m}$. Choosing this value to estimate the surface lowering of a typical collapse doline in nature, leads to $\mathrm{a} \approx 100 \mathrm{~m}$ deep doline after $\approx 450000$ years. This is an acceptable time frame for the creation of a large collapse doline. Note that collapse dolines in the Dinaric karst of southern Europe are assumed to have developed during millions of years, whereas the Tiankengs in China may be as young as 200000 years (Zhu \& Chen 2006, Zhu \& Waltham 2006).

\subsubsection{MODEL $2 \& 3$ - THREE ACTIVE CRUSHED ZONES}

Now that we have presented a model for the creation of one single collapse doline we want to focus on the interplay of three dolines within one model. Therefore, not only the CZ2 along passage 2 is activated but also two different scenarios for the position of CZ3 are tested. In the first case (model 2) CZ3 is placed close to CZ1 whereas in the second case (model 3) CZ3 is placed further downstream (for the layout see Fig. 3 and Tab. 2). 


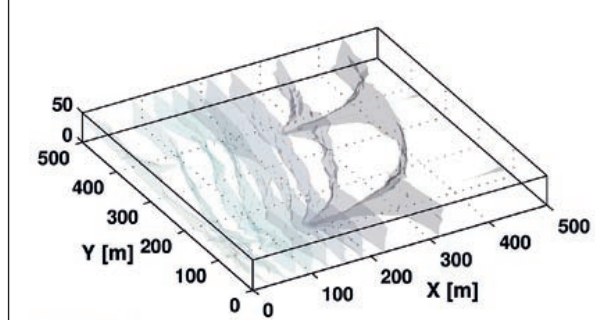

a) year: 0

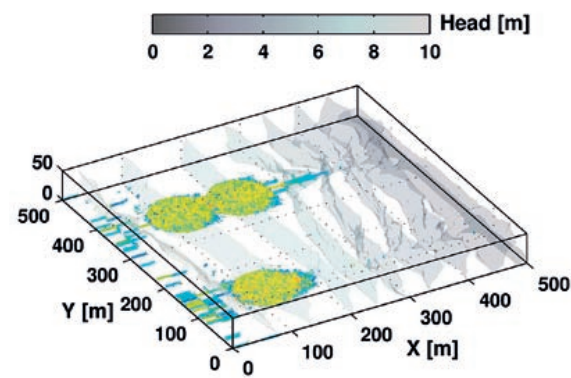

c) year: 1300

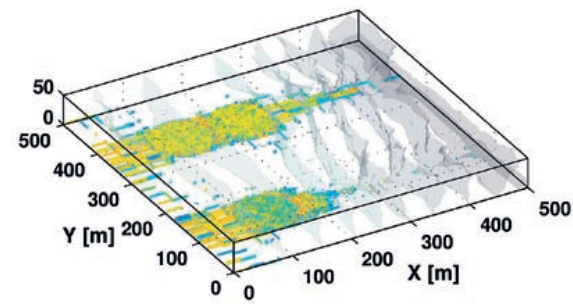

e) year: 3000

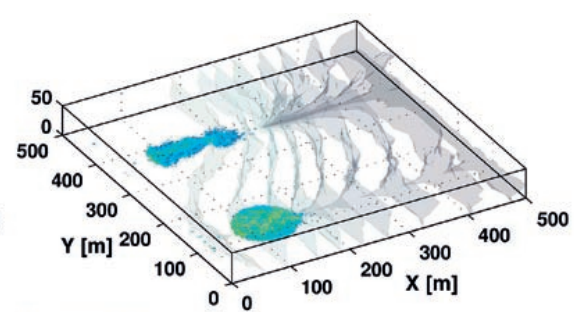

b) year: 300

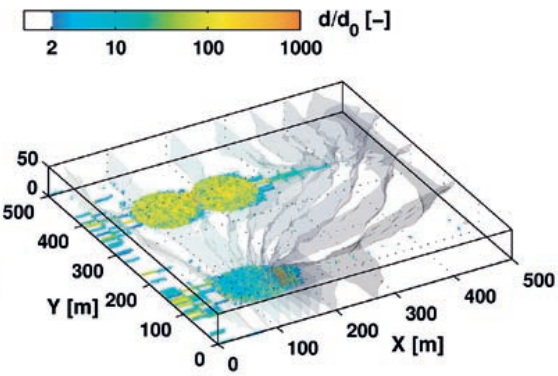

d) year: 1420

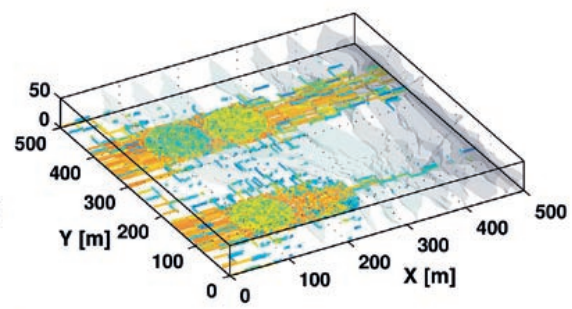

f) year: 6000
Fig. 7: Conduit diameter evolution of the $3 D$ doline model 2 (three active crushed zones) for different snapshots in time. Below each subplot the year is given; plotted are the isosurfaces of constant head from low (dark grey) to high (light grey) values and the relative increase of the conduit diameter compared to the initial diameter on a log-scale from 2 (blue) to $\geq 1000$ (orange).
In this section we will simultaneously describe the evolution of model $2 \& 3$ and highlight only the differences in their evolution. The evolution snapshots for model $2 \& 3$ can be found in Fig. 7 and Fig. 8, respectively. The color codes for the head distribution and the conduit diameter increase are the same as for model 1 (Fig. 6).

The initial head distribution (subfigures a) already reveals that the effect of more than one active crushed zone within the model domain is recognizable. When the two active crushed zones along passage 1 are closer together (model 2) then the evolution of the downstream crushed zone allows for higher flow rates and hence more effective development than for the single crushed zone case (model 1). This effect is less pronounced in model 3 which looks initially more like model 1 , due to the greater distance between CZ1 and CZ3. After 300 years of evolution two major differences, in comparison to model 1 , are visible. In both cases (model $2 \& 3$ ) the crushed zones have evolved slower than the single crushed zone and also the general flow field inside the domain is different. Both observations are directly linked to the decreased hydraulic gradients along passage 1 . The first effect follows consequently from the reduced flow along passage 1 and is therefore the cause for the weaker evolution. The distortion of the flow field in models 2 \& 3 potentially also allows flow from passage 1 towards the single crushed zone and passage 2 which was not the case for model 1. There, the head isosurfaces are almost parallel along the not activated passage 2. But comparing the evolution of the single crushed zone in all three models, the evolution in model $2 \& 3$ seems to be not much effected by the other two crushed zones or the effect is just not resolvable with our simulation.

As for model 1, also for model $2 \& 3$ the first collapse event happens for the single crushed zone after $\approx$ 1400 years of evolution. However, one difference can be recognized when comparing the evolution of the volume loss over time for the single crushed zone in model 2 \& 3 with model 1 (Fig. 9b,d,f). As for model 1 also in model 2 the initial collapse of all layers happens within one time step at $\approx 1400$ (curves start at $\approx 2000 \mathrm{~m}^{3}$ ). For model 3 the curve for CZ2 starts at $\approx 400 \mathrm{~m}^{3}$, indicating that only one layer collapsed at that time with the other layers following shortly after. This effect is again visible after $\approx 5000$ years of evolution when the jump of vol- 


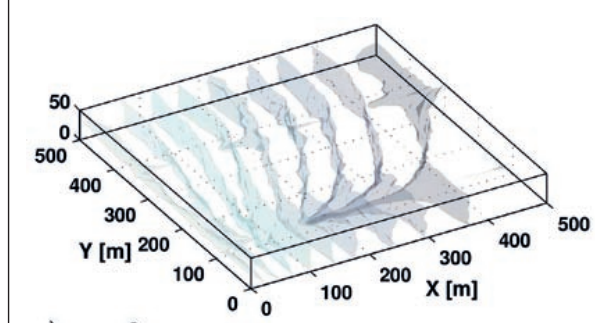

a) year: 0

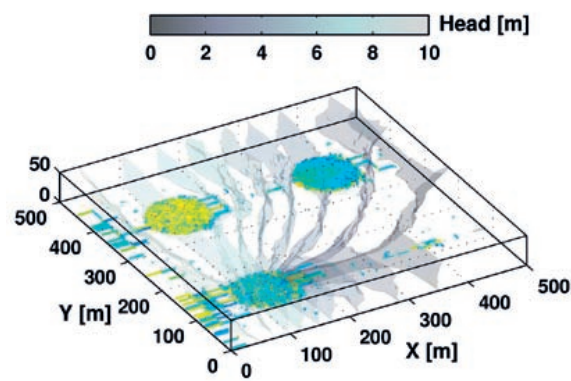

c) year: 1430

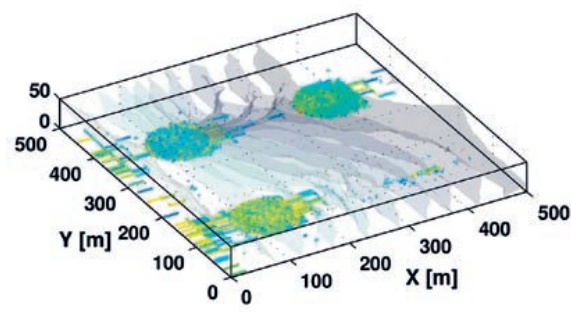

e) year: 1850

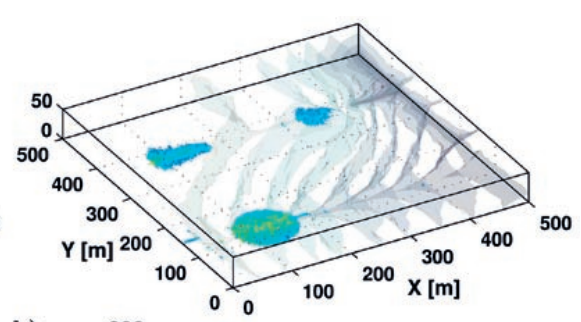

b) year: 300

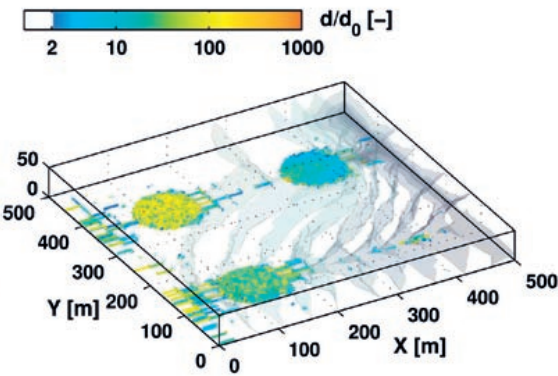

d) year: 1680

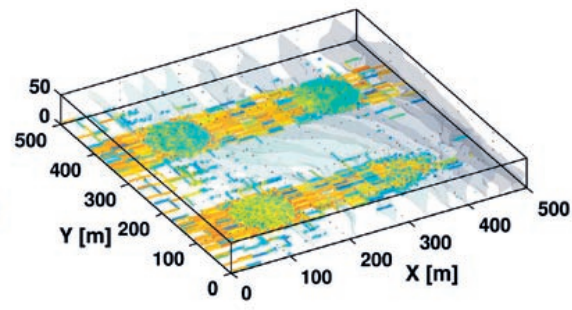

f) year: 6000
Fig. 8: Conduit diameter evolution of the $3 D$ doline model 3 (three active crushed zones) for different snapshots in time. Below each subplot the year is given; plotted are the isosurfaces of constant head from low (dark grey) to high (light grey) values and the relative increase of the conduit diameter compared to the initial diameter on a log-scale from 2 (blue) to $\geq 1000$ (orange). ume loss for CZ2 in model 2 occurs from $\approx 6000 \mathrm{~m}^{3}$ to $\approx 8000 \mathrm{~m}^{3}$ within a single time step whereas for model 3 this jump shows again a small kink indicating consecutive collapse events. As already stated above, these effects are rather minor and may be addressed in more detail in a future study. Here we focus on the interplay of two crushed zones along one subsurface passage.

After $\approx 1700$ years of evolution the first collapse event happens in both models $2 \& 3$ in CZ3, but with different magnitude. In model 2 four layers inside CZ3 collapse shortly after each other, in model 3 only 2 layers collapse. This is due to the different head values within the crushed zones, which causes several layers of the crushed zone to be above the water table and therefore not affected by dissolution. In model 3 where CZ3 is further downstream of $\mathrm{CZ} 1$ this effect is stronger. The first collapse of CZ1 in both models $2 \& 3$ happens shortly after CZ3 but with a stronger amplitude indicating that all active layers within the crushed zone have been collapsed.

From Fig. 9c-f we see that the periodicity of collapse events for CZ1 follows the one of the single crushed zone CZ2 with a time-lag of $\approx 450$ years. Initially this also counts for CZ3 in model 2. The second collapse event happens at the same time as for $\mathrm{CZ} 1$ at $\approx 3000$ years but with fewer layers. The remaining collapse of the other layers happens several hundred years later. The third collapse of CZ3 in model 2 is now completely shifted $\approx 500$ years after the collapse of CZ1. The whole evolution of CZ3 is slowed down. In model 3 the second collapse of CZ3 is no longer a single event but a series of individual events between 3300-3500 years. The shift in the periodicity of collapse events between CZ1 and CZ3 is even stronger in model 3 than in model 2. This can be explained by the fact that the evolution of the higher layers in CZ3 stops completely every time CZ1 collapses. Then, only the lowermost layer(s) in CZ3 are below the watertable and supplied by fresh aggressive water. Individually, all three dolines show the periodicity in their evolution, only the onset and the amplitude of the individual collapse events differ due to the effect the dolines have on each other. The slowing down of the evolution of CZ3 persists throughout the whole simulation of model $2 \& 3$ and leads to a difference in topographic height between $\mathrm{CZ1}$ and $\mathrm{CZ3}$ of $\approx 0.3 \mathrm{~m}$ (model 2$)$ and $\approx 0.6 \mathrm{~m}$ (model 3 ) after 6000 years of evolution. 

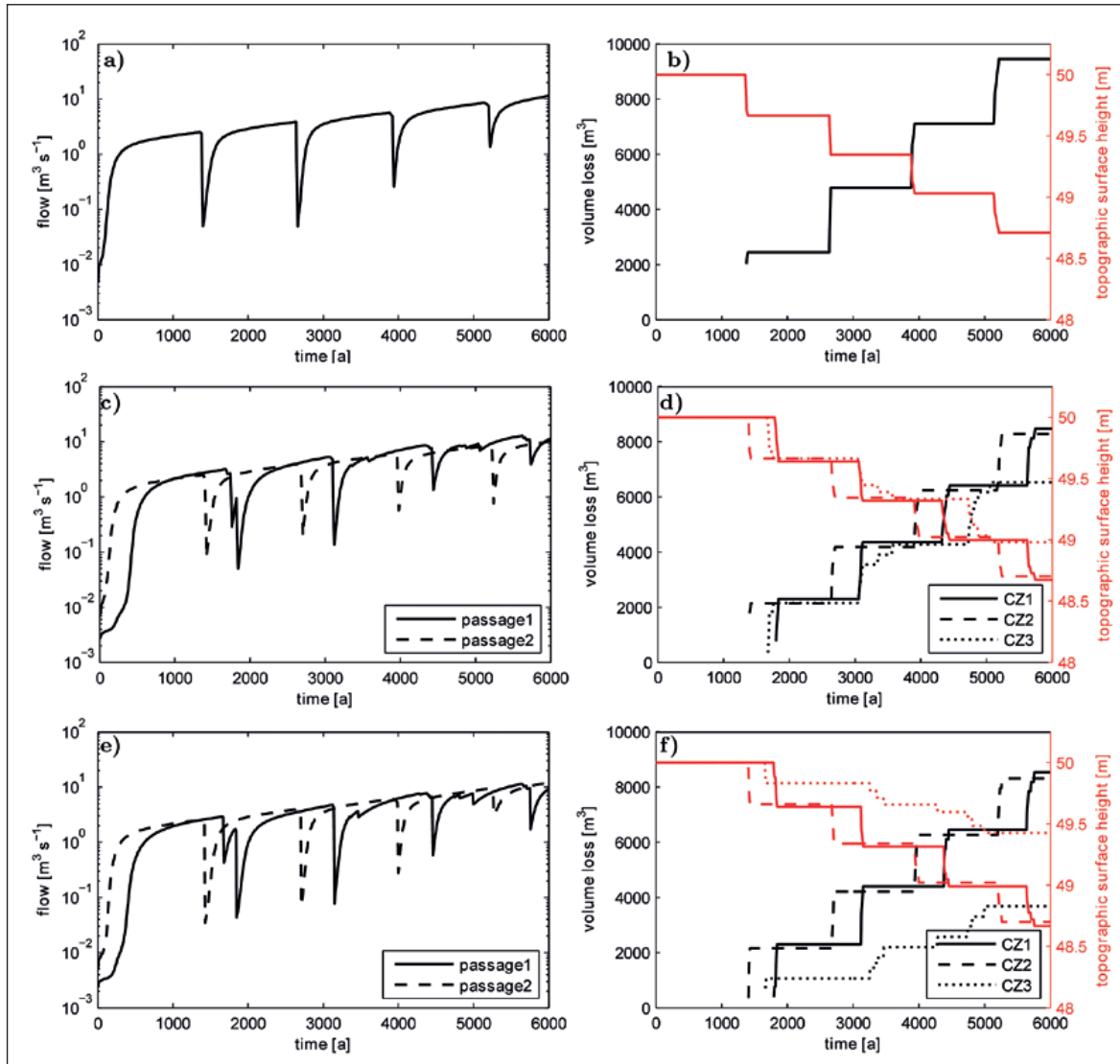

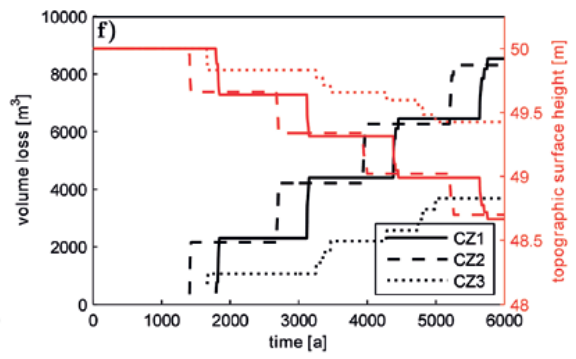

Fig. 9: Flow curves and surface data for the three models. $a, c, e$ ) flow rates at the exit of passage 1 (all models) and 2 (only model 2 \& 3); $b, d, f$ ) cumulative surface volume loss (black) and topographical height (red) above the crushed zone(s) for b) model 1, d) model 2 and f) model 3 .
For the three-doline-models shown here, two major observations can be made in Fig. 9c-f: First, if two potential dolines are connected via a subsurface passage, the downstream doline slows down the evolution of the upstream doline compared to the single doline case by $\approx 400$ years in our model. Considering the fact that this model is highly simplified, one can easily imagine how this effect is even stronger when multiple dolines are connected via a common karst system involving also a branched network of passages. Our model shows that a single large collapse doline can evolve quite fast if not disturbed by a group of dolines and that the surface lowering (material removal) is in accordance with values reported in the literature. Secondly, the further away a doline out of a connected group is located downstream, the more its evolution is slowed down, or eventually even stopped. The slow-down for CZ3 is approx. a factor of 3 in the lowering of the surface (model 3).

\section{CONCLUSION}

There are several conditions that have to be fulfilled for a large collapse doline to evolve (see Waltham et al. 2005; Kranjc 2006; Waltham 2006; Zhu \& Chen 2006; Zhu \& Waltham 2006). A doline with tens to hundreds of meters width and depth, with very steep walls and a floor full of debris, can develop above an active cave system, or above a highly permeable, mechanically unstable zone within a karst aquifer. Furthermore, a necessary condition is that a large amount of water (a subsurface river for example) flows through this system and guarantees the effective dissolution of the soluble host rock.

Following the hypothesis of Palmer and Palmer (2006), Gabrovšek and Stepišnik (2011) developed a 2D numerical karst evolution model to simulate the initiation and evolution of a collapse doline. The outcome of this numerical simulation supports the hypothesis of Palmer and Palmer (2006), and concludes that within a reasonable time frame a collapse doline can develop. 
A first goal of our work was to verify the above mentioned conditions with the help of a 3D numerical karst evolution model. In this way we address the main shortcoming of the model presented by Gabrovšek and Stepišnik (2011), namely that all the water was pushed through a single layer of an active crushed zone, which possibly can lead to an overestimation of the rate of material removal/surface lowering and an underestimation of the time required for a doline development. Our results confirm the conclusions suggested by Palmer and Palmer (2006) and Gabrovšek and Stepišnik (2011) and demonstrate that for simple geological settings (a single crushed zone with a large subsurface river flowing at its bottom) the above mentioned conditions are sufficient to predict and explain the development of a large collapse doline. Furthermore, we show that a 2D karst evolution model can describe the evolution of an isolated doline sufficiently well, allowing the development of models describing real location with very high spatial resolution.

The second goal of our study was to extend the $3 \mathrm{D}$ karst evolution model in space and to simulate the evolution of complex systems of collapse dolines. The results show that also for these complex geological settings, the main processes governing the growth of large dolines remain valid. We demonstrate that the interactions between the growing dolines are very complex and that the distance between the dolines and the hydro-geological local conditions around them can influence the location of maximum rock dissolution, the frequency of the collapsing events and the time scale of the doline development. This means that for areas above long active cave passages, one would need a detailed knowledge and a dense network of geophysical investigations in order to be able to point the zones of possible sinkhole or dolines development. This result is especially important for locations in the vicinity of large hydraulic structures or large infrastructure projects.

Finally, we would like once again to underline that the goal of the paper is to verify the hypothesis for development of collapse dolines presented by Palmer and Palmer (2006) and to extend the earlier verification of this hypothesis presented by Gabrovšek and Stepišnik (2011). What we present is a synthetic model based on these publications. All results presented here are valid within this synthetic model. A direct application of these results to real collapse dolines as part specific case studies has to be done with care. This is especially valid for locations, for example very large collapses, where an account for the mechanical erosion and the rock mechanics is required. Our model has to be further developed in order to be able to describe such places. This will be the topic of further publications.

\section{ACKNOWLEDGEMENTS}

We would like to thank the German Research Society (Deutsche Forschungsgemeinschaft - DFG) for funding the Project KA1723/6 within this work was prepared.
Furthermore, the constructive and very helpful reviews provided by two anonymous reviewers were of a great help when preparing this manuscript.

\section{REFERENCES}

Buhmann, D. \& W. Dreybrodt, 1985a: The kinetics of calcite dissolution and precipitation in geologically relevant situations of karst areas: 1 . Open system.Chemical Geology, 48, (1-4), 189-211.

Buhmann, D. \& W. Dreybrodt, 1985b: The kinetics of calcite dissolution and precipitation in geologically relevant situations of karst areas: 2 . Closed system.Chemical Geology, 53, (1-2), 109-124.

Dreybrodt, W., 1988: Processes in Karst Systems - Physics, Chemistry and Geology.- Springer Series in Physical Environments 4, Springer Berlin, New York.
Eisenlohr, L., Meteva, K., Gabrovšek, F. \& W. Dreybrodt, 1999: The inhibiting action of intrinsic impurities in natural calcium carbonate minerals to their dissolution kinetics in aqueous $\mathrm{H}_{2} \mathrm{O}-\mathrm{CO}_{2}$ solutions.Geochimica et Cosmochimica Acta, 63, (7-8), 9891001.

Gabrovšek, F. \& U. Stepišnik, 2011: On the formation of collapse dolines: A modelling perspective.- Geomorphology, 134, 23-31.

Harned, H. S. W. J. \& Hamer, 1933: The ionization constant of water.- J. Am. Chem. Soc., 55, 693-695. 
Hiller, T., Kaufmann, G. \& D. Romanov, 2011: Karstification beneath dam-sites: From conceptual models to realistic scenarios.- Journal of Hydrology, 398, 202-211.

Istok, J. D., 1989: Groundwater Modeling by the Finite Element Method - American Geophysical Union, pp 495, Washington.

Kaufmann, G., 2009: Modelling karst geomorphology on different time scales.- Geomorphology, 106 (1-2), 62-77.

Kaufmann, G. \& W. Dreybrodt, 2007: Calcite dissolution kinetics in the system $\mathrm{CaCO}_{3}-\mathrm{H}_{2} \mathrm{O}-\mathrm{CO}_{2}$ at high undersaturation.- Geochimica et Cosmochimica Acta, 71 (6), 1398-1410.

Kaufmann, G., Romanov, D. \& T. Hiller, 2010: Modeling three-dimensional karst aquifer evolution using different matrix-flow contributions.- Journal of Hydrology, 388 (3-4), 241-250.

Kranjc, A., 2006: Some large dolines in the Dinaric karst.- Speleogenesis and Evolution of Karst Aquifers, 4 (9), 1- 4 .

Palmer, A. N. \& M. V. Palmer, 2006: Hydraulic processes in the origin of tiankengs.- Speleogenesis and Evolution of Karst Aquifers, 4 (9), 1-8.

Plummer, L. N., Wigley, T. M. L. \& D. L. Parkhurst, 1978: The kinetics of calcite dissolution in $\mathrm{CO}_{2}$ - water systems at $5^{\circ} \mathrm{C}$ to $60{ }^{\circ} \mathrm{C}$ and 0.0 to 1.0 atm $\mathrm{CO}_{2}$. $^{-}$ American Journal of Science, 278, 179-216.
Raines, T. W., 1967: Sótano de las Golondrinas.- Bulletin of the Association for Mexican Cave Studies, 2, $1-37$.

Romanov, D., Kaufmann, G. \& T. Hiller, 2010: Karstification of aquifers interspersed with non-soluble rocks: Fom basic principles towards case studies.- Engineering Geology, 116 (3-4), 261-273.

Svensson, U. \& W. Dreybrodt, 1992: Dissolution kinetics of natural calcite minerals in $\mathrm{CO}_{2}$ - water systems approaching calcite equilibrium.- Chemical Geology 100 (1-2), 129-145.

Usdowski, E., 1982: Reactions and equilibria in the systems $\mathrm{CO}_{2}-\mathrm{H}_{2} \mathrm{O}$ and $\mathrm{CaCO}_{3}-\mathrm{CO}_{2}-\mathrm{H}_{2} \mathrm{O}$ $\left(0^{\circ}-50{ }^{\circ} \mathrm{C}\right)$.- N. Jb. Miner. Abh., 144 (2), 148-171.

Waltham, T., 2006: Tiankengs of the world, outside China.- Speleogenesis and Evolution of Karst Aquifers 4 (9), p. 1.12.

Waltham, T., Bell, F. G. \& M. G. Culshaw, 2005: Sinkholes and Subsidence.- Springer Berlin, Heidelberg, pp 282, New York.

Zhu, X. \& W. Chen, 2006: Tiankengs in the karst of China.- Speleogenesis and Evolution of Karst Aquifers, 4 (9), 1-18.

Zhu, X. \& T. Waltham, 2006: Tiankeng: definition and description.- Speleogenesis and Evolution of Karst Aquifers, 4 (9), 1-8. 